\title{
A patrimonialização e suas contradições: o patrimônio prisional na França do tempo presente
}

Viviane Trindade Borges"

Resumo: O presente artigo objetiva traçar os embates em torno das práticas de patrimonialização de espaços prisionais na França. Tendo como fio condutor o caso da Prison de La Santé, aberta à visitação pública durante as Jornadas do Patrimônio de 2014, intenciona-se tornar compreensível o debate e algumas implicações teórico-metodológicas enfocadas na constituição de um conceito ainda em construção, o de patrimônio prisional (ou patrimônio carcerário), o qual vem fomentando discussões na França nos últimos dez anos. Objetiva-se analisar os destinos contraditórios de algumas prisões do século XIX ainda em funcionamento e/ou desativadas, edificações monumentais tornadas obsoletas na atualidade e marcadas pelos conflitos que cercam os caminhos contraditórios de algumas ações de patrimonialização, bem como problematizar o papel de alguns historiadores nesse processo.

Palavras-chave: Patrimônio prisional. Prisões. História do tempo presente. França.

\section{Introdução}

No ano de 2014, em Paris, conduzidas por um guia, um psiquiatra e um ex-detento, cerca de 1500 pessoas visitaram a Prison de la Santé durante as Jornadas do Patrimônio, evento que ocorre anualmente e durante o qual o governo francês abre alguns lugares

\footnotetext{
"Professora na Universidade do Estado de Santa Catarina (UDESC). Doutorado em História pela Universidade Federal do Rio Grande do Sul (UFRGS). E-mail: vivianetborges@gmail.com, https://orcid.org/0000-0002-7576-7789
} 
A patrimonialização e suas contradições: o patrimônio prisional...

considerados históricos e comumente restritos ao acesso público. As visitas à instituição, em funcionamento desde 1867 e temporariamente desativada em 2014, tiveram as reservas esgotadas em duas horas. Aberta pela primeira vez ao público, os visitantes puderam descobrir um lugar considerado "extraordinário e onde ninguém geralmente quer entrar"1.

A Prison de La Santé foi temporariamente fechada em 2014 para reformas em que preveem intervenções que vão descaracterizar em prol de modernizar um lugar atualmente considerado antiquado e inapropriado. Em seus primeiros anos de funcionamento, na segunda metade do século XIX, a penitenciária exibia o que de mais moderno existia na época, como celas equipadas com iluminação a gás, aquecimento e água nos banheiros, saneamento ainda raro no restante da cidade. A situação de La Santé se deteriorou ao longo dos anos e, a exemplo do que ocorre em várias instituições do gênero, a superlotação tornou-se uma constante desde o final do século XIX, estendendo-se pelo século XX e XXI, acompanhada por fugas e rebeliões de presos, levando a discussões que previam sua destruição já na década de 60 (FIZE, 2015).

"La Santé não é um museu, mas sua presença nas Jornadas do Patrimônio parece óbvia para o visitante"2, aponta uma reportagem sobre as curiosidades da visita. Apesar da suposta naturalidade sobre a importância patrimonial da instituição prisional, nada vem sendo pensado para tentar impedir sua descaracterização. Por que o interesse despertado nos visitantes não interfere nas ações de apagamento dos espaços prisionais?

Apesar de um presente exacerbado de memória, nos mantemos indolentes com aquilo que foge à regra, como no caso das prisões, "delas nada se quer guardar" (SANTOS, 2013, p. 222). O interesse em estudar o passado próximo é marcado por "fortes tensões entre a necessidade da lembrança e o atrativo do esquecimento" (ROUSSO, 2016, p. 24). No caso das prisões, o "atrativo do esquecimento" tem superado a "vontade de memória" (NORA, 1993, p. 22), provocando embates que vêm ganhando contornos conflituosos em muitos países, como é o caso da França. Pretendo aqui delinear uma possível inteligibilidade de um discurso conflitante que por vezes confere valor patrimonial àquilo que parece desejar esquecer, apagar, demolir. 
A noção de patrimônio invadiu o espaço público, possibilitando "políticas públicas do passado", tornando o passado recente um problema a ser enfrentado, confrontado, resolvido, superado (ROUSSO, 2016, p. 29). Tendo como fio condutor o caso da Prisão de La Santé, traçarei as tensões em torno das práticas de patrimonialização de espaços prisionais franceses. Os casos citados servem para tornar compreensíveis as questões teóricas e metodológicas enfocadas na constituição de um conceito ainda em construção, o de patrimônio prisional (ou patrimônio carcerário), o qual vem fomentando discussões na França nos últimos dez anos, marcadas pelas dúvidas e desafios que perpassam pela ampliação da noção de Patrimônio a partir dos anos 90 (MARTIN, 2015).

Primeiramente, tratarei dos destinos contraditórios desses patrimônios monumentais tornados obsoletos na atualidade. $\mathrm{Na}$ sequência, problematizarei o papel de alguns intelectuais, entre eles historiadores, nesse processo, bem como os embates que cercam a emergência do referido conceito. $\mathrm{O}$ debate entre historiadores e a imprensa marca uma das características indeléveis do tempo presente, ou seja, a preocupação com o diálogo público que extravasa as dimensões acadêmicas. A presença de historiadores e a reverberação de seus debates nos meios de comunicação possibilitaram a constituição de novas fontes, trazendo questões que relacionam a história do tempo presente a "sua função de conhecimento e sua função social” (DELACROIX, 2018, p. 48). O presente artigo problematizará fontes que pululam em diferentes sites da internet $\mathrm{e}$ fazem parte do debate que cerca os destinos dos espaços prisionais na atualidade.

\section{Monumentais e obsoletas: contradições}

Monumentais, projetadas para expressar a modernidade das cidades, as prisões construídas no século XIX, muitas ainda em funcionamento no século XX e XXI, são expressões de uma arquitetura específica, voltada a objetivos próprios: fabricar corpos dóceis. Conforme explicitado por Michel Foucault (2002), da dor dos suplícios públicos à tessitura das penas cumpridas atrás dos muros 
A patrimonialização e suas contradições: o patrimônio prisional...

institucionais, a nova racionalidade da punição, através de um espaço celular no qual os presos são confinados, dá ênfase a um projeto arquitetônico estruturado como instrumento da punição. A prisão reúne os corpos em sua arquitetura fechada. As paredes, as celas, os muros, assim como as marcas deixadas por aqueles que passaram por esses espaços, fazem parte desse mecanismo de saber/poder que tece as práticas institucionais através da privação da liberdade. A lógica interna desses espaços, as regras inseridas às práticas institucionais, os lugares destinados aos corpos confinados e a apropriação que estes faziam do lugar em seu uso cotidiano só podem ser desvelados se tais espaços e suas marcas forem preservados.

Tais estruturas e seus embates éticos também seriam parte de nossa "herança cultural"? Seriam relíquias que a sociedade deseja guardar? Podemos entender as prisões sob essa perspectiva tradicional de patrimônio? Ou elas seriam nossa "Herança Obscura"? Se no século XX o patrimônio assume de forma explícita uma atribuição de valores que afirma de fato uma escolha (POULOT, 2006, p. 9), como dar inteligibilidade aos apagamentos do patrimônio ligado às prisões? Como vêm se operando essas escolhas e quais caminhos têm sido trilhados?

Muros altos de pedra ornados com arame farpado afiado. Situada no charmoso bairro de Montparnasse, as edificações austeras da prisão de La Santé, que anteriormente abrigaram (no século $\mathrm{XIII)}$ as vítimas da peste, parecem afrontar os típicos e elegantes edifícios haussmanianos das ruas parisienses. $\mathrm{O}$ projeto que prevê a requalificação do local procura sua "integração" à bela paisagem da cidade luz. Um desejo de reprimir sua dissonância, possibilitando que as edificações remodeladas passem despercebidas a olhos menos atentos, como parte harmônica do tecido urbano que até então não parecia absorvê-las ${ }^{3}$. Única prisão de Paris ainda em funcionamento em perímetro urbano, La Santé é tida como um marco da história das prisões na França. A última reforma ocorreu em 1945, quando 6 mil homens ocupavam o lugar, excedendo a capacidade institucional em 6 vezes. O lugar abrigou presos condenados à morte, entre 1909 e 1972, possuindo em seu acervo a velha guilhotina em desuso. Os detentos mais conhecidos que passaram pela instituição, chamados de "Vips" devido a algumas regalias a eles conferidas nos 
espaços ocupados dentro da prisão, são frequentemente citados pela imprensa e alguns já motivaram documentários, livros e filmes, como o terrorista Carlos ${ }^{4}$, o general Noriega ${ }^{5}$, "o inimigo público $\mathrm{n}^{\mathrm{a}} 1^{\text {” Jacques Mesrine }}{ }^{6}$, Maurice Papon ${ }^{7}$, entre outros.

Conforme Andrew Hussey, diretor do Centro de Estudos Avançados da Escola de Estudos Pós-coloniais da Universidade de Londres, "além da Bastilha, esta é a prisão mais famosa da história francesa". Hussey compara La Santé aos antigos mictórios públicos de Paris, desativados e destruídos na década de 1990, os quais, segundo ele, "também tiveram papel menor mas crucial na história cultural da cidade", servindo como ponto de encontros eróticos para gays e local secreto de atividades ligadas à resistência francesa durante a Segunda Guerra Mundial. Na visão de Hussey, de forma semelhante ao último mictório público ainda existente na cidade, bem próximo às paredes da velha prisão, La Santé também representa "um monumento espectral a uma Paris antiga, muito distante da elegante cidade do século XXI".

A comparação, de certa forma depreciativa, instaura La Santé como um patrimônio marcado por questões conflituosas. A matéria, publicada pelo jornal inglês The Guardian, afirma que a prisão é "histórica", "um local de memória" para os franceses, procurando definir brevemente o conceito proposto por Pierre Nora (1993): "um termo usado por historiadores franceses para denotar edifícios e monumentos carregados de significado histórico". Amplamente usado em diferentes contextos e não apenas por historiadores, o conceito ganhou assimilações distintas, difusas e, por vezes, contraditórias, que em alguns casos se distanciam da problematização crítica a respeito dos usos do passado e das disputas de memórias, propostas por Nora, ocasionando, muitas vezes, uma banalização laudatória sobre o passado recordado. O "significado histórico" é algo atribuído ao patrimônio, uma construção que sanciona e atribui posição de destaque a determinados objetos, práticas, edificações (POULOT, 2006). Apesar da importância patrimonial e histórica conferida a La Santé, a qual possibilitou sua inscrição nas Jornadas do Patrimônio, quando encerrarem as obras iniciadas em 2014 pouco restará de original no monumental edifício. 
A patrimonialização e suas contradições: o patrimônio prisional...

As Jornadas do Patrimônio, atualmente chamadas de Jornadas Europeias do Patrimônio, colocam em evidência a presença do patrimônio nos espaços públicos, exibindo diferentes lugares e instituindo o que deve ser visitado. François Hartog (2017, p. 43-44) questiona se a fase ascendente do patrimônio vem dando ( espaço a um refluxo, uma fase ordinária: da invenção passamos à digestão. Não seria mais o tempo dos manifestos, mas de pensar sobre o que conservar, considerando que deve servir à vida, sob a perspectiva de uma economia do patrimônio. Nesse sentido, as ações de patrimonialização objetivam menos "preservar para transmitir do que para tornar mais habitável o presente e preservá-lo por ele mesmo: primeiro para seu próprio uso". O que se questiona aqui é a própria transmissão (HARTOG, 2017, p. 44). A preservação garantiria a transmissão do patrimônio cultural às gerações futuras. Os processos de transmissão remetem a uma vontade de continuidade, mas não podemos esquecer que o "conjunto de bens que constitui o patrimônio coletivo não depende de critérios e escolhas individuais ou de grupos, mas está intimamente ligado à própria dinâmica social” (MAGNANI, 1886). No caso das prisões, de que forma vem se operando essa transmissão? O que ela exclui e delega ao apagamento? Existe lugar para esses patrimônios na atual dinâmica social?

No que tange à proteção legal, os edifícios prisionais franceses parecem merecer o registro como monumentos históricos apenas quando sua história tenha sido atravessada por eventos relacionados à Segunda Guerra Mundial, evidenciando o "lugar eminente" do evento como tema e campo de pesquisa privilegiado pela história do tempo presente na França (DELACROIX, 2018, p. 44). Conforme salienta Hartog, a própria expressão "lugar de memória” entrou para o dicionário Larousse, em 2003, fazendo referência a episódios ligados à Segunda Guerra como exemplos para a compreensão do conceito: "A obrigação moral de testemunhar, individual ou coletivamente, os acontecimentos cujo conhecimento e transmissão são julgados necessários para tirar as lições do passado (na Resistência ou a deportação durante a Segunda Guerra Mundial, por exemplo)" (HARTOG, 2017, p. 36). Nos demais casos, a "obrigação moral" ligada à preservação tem sido incerta e marcada por embates. 
Os rearranjos que promovem a desativação, demolição e/ou reforma de algumas prisões e penitenciárias francesas se devem, em muitos casos, à decisão do governo de fechar estabelecimentos penais que desrespeitavam os direitos humanos, ocasionando o fechamento de 27 instituições consideradas obsoletas somente em 2001. Assim, "parte significativa do parque prisional herdado do século XIX - às vezes até em períodos mais antigos, quando se trata de propriedade nacional reformada - está condenada à destruição" (VIMONT, 2008, p. 196).

$\mathrm{Na}$ atualidade, algumas prisões francesas têm encontrado destinos contraditórios. Em 1990, a prisão de Mont-de-Marsan, construída entre 1807 e 1809, foi parcialmente classificada como monumento histórico. A prisão de Avignon, do século XIII, foi vendida em 2017 e em breve deve se tornar um hotel de luxo. A prisão de Nancy, do início do século XVIII, deve ser destruída. Por fim, prisões como as de Lyon, Rennes ou Toulouse permanecem sem definições certas a respeito de seus destinos (SOPPELSA, 2010a). O caso das prisões de Lyon vem gerando debates na imprensa promovidos pelos "defensores da memória e do patrimônio", que alegam que a transformação do lugar em campus para a Universidade Católica, moradias, escritórios e empresas, garantem apenas minimamente a preservação das edificações. As duas prisões formam um complexo que representa "um testemunho único da arquitetura da prisão francesa do século XIX", atualmente ameaçado pela proposta de modernização de edificações tidas como obsoletas ${ }^{10}$.

No caso de La Santé, a justificativa benevolente para descaracterização do lugar, em prol dos direitos humanos, coaduna com o apontado no documento "Estratégias para o Patrimônio no Século XXI"11, o qual frisa que "as políticas patrimoniais contribuem para a melhoria do ambiente de vida e da qualidade de vida dos europeus e desempenham um papel significativo no fortalecimento do tecido social e do progresso econômico" ${ }^{12}$. Frente a esse cenário, apesar da popularidade de La Santé, o projeto em execução prevê sua descaracterização em prol de melhorias. No caso das prisões, as demolições são quase sempre associadas a uma promessa de futuro (SANTOS, 2013, p. 223), como se a destruição das edificações exorcizasse uma herança obscura e o apagamento de evidências materiais contribuísse para o esquecimento e ressignificação desses lugares. 
Em 2018, o canal francês $R M C$ Découvert instituiu a importância e a monumentalidade da reforma de La Santé através de um documentário disponível no youtube, que atualmente conta com 7,2 mil visualizações. Nele pouco se fala em demolição, mas sim em revitalização e requalificação, frisando a precariedade das edificações e a tecnologia empregada para garantir o bem-estar da população, permitindo que a instituição assuma novamente o "status de prisão exemplar". Apesar da composição de significados a respeito do lugar ser fundamentada na importância de seu caráter histórico, corroborada pelos depoimentos de historiadores e arquitetos, o documentário destaca que o velho prédio não é classificado como monumento histórico, o que parece autorizar as intervenções como necessárias e positivas ${ }^{13}$.

A reforma de La Santé se insere, portanto, em um projeto que busca melhorar a imagem das prisões francesas, principalmente após a publicação do livro de Véronique Vasseur (2000), médica-chefe de La Santé, intitulado "Médecin-chef à la prison de la Santé". O relato de Vasseur sobre La Santé chocou os franceses:

Ela descreveu que o lugar estava infestado de ratos e baratas, os presos estavam empilhados uns sobre os outros, prisioneiros suicidas eram deixados acorrentados (beber desinfetante era uma das formas mais comuns de tentar se matar). Havia o tipo de ferimentos graves geralmente vistos apenas em tempos de guerra [...] e outras infecções de pele consideradas deixadas para trás no século XIX. O mais chocante para todos os leitores foi que La Santé era uma "cidade dentro da cidade", com suas próprias regras e uma moralidade governada pela violência e pela falta de lógica. A prisão aparentemente foi abandonada pelas autoridades francesas para a doença e a morte ${ }^{14}$.

Em 2012, o livro inspirou um filme com o mesmo título, atualizando aspectos da tragédia prisional francesa e contribuindo para legitimar a necessidade de intervenção do Estado em La Santée O processo de acelerada destruição de edificações penitenciárias do século XIX e início do XX mostra os embates que cercam as 
discussões ligadas à patrimonialização de lugares ainda em uso e marcados por contradições do tempo presente, desconsiderando "a legitimidade do pertencimento desse tipo de edificação à memória coletiva" (SOPPELSA, 2010, p. 83). De forma geral, o caráter patrimonial procura investir de sentidos ligados à memória e à história algo que se refere ao passado, contudo, no caso das prisões, a discussão segue reverberando no presente (BORGES, 2018a). Os embates que cercam a patrimonialização das prisões trazem à tona uma herança incômoda que provoca, entre outras coisas, questionamentos à memória e aos usos do passado, e desestabiliza as certezas das práticas de seleção e preservação.

Cabe ressaltar ainda a ausência de museus consagrados aos lugares de confinamento na França, principalmente se pensarmos tais práticas nos séculos XIX e XX. O Museu Nacional das Prisões, único no país, funcionou apenas entre 1995 e $2010^{16}$, e nunca teve suas coleções totalmente abertas ao público. Em uma Jornada de estudos destinada a pensar o patrimônio prisional, realizada em 2017 pela Universidade de Rennes, o tema foi discutido por profissionais do campo do patrimônio, historiadores e arquitetos. $\mathrm{O}$ caso francês contrasta ao que vem ocorrendo em lugares como os Estados Unidos (WELCH, 2015) e Canadá (WALBY; PICHÉ, 2011), onde museus e memoriais de prisão vêm sendo criados nos últimos anos. Não obstante, "um presente aparentemente tolerante e benevolente perante os vestígios do passado, em que tudo se torna passível de ser investido de sentidos patrimoniais, seguimos assistindo a sistemáticos apagamentos de edificações dissonantes” e seus vestígios (BORGES, 2018b).

\section{Privação de liberdade, privação de memória}

Em 1974, Michel Foucault, acompanhado de outros intelectuais, arquitetos, historiadores de arte e filósofos, se reuniram em frente à prisão La Petite Roquette ${ }^{17}$, em Paris, para protestarem contra a demolição do lugar (PERROT, 1989). Eles criaram a Associação para a Salvaguarda do Panóptico de La Petite Rocket (APSPPR) $)^{18}$. A instituição, construída entre 1830 e 1836, é parte das Prisões de $L a$ 
Roquette, e conheceu várias funções ao longo dos anos: depósito de sentenciados a penas leves, casa de correção para as mulheres e em 1835 passa a abrigar jovens em conflito com a lei, tornando-se Casa da Educação Correcional (GUERIN, 2014) ${ }^{19}$. Em 1974, um programa de rádio, Les après-midi de France Culture, trazia Michel Vernes, professor de Belas Artes e diretor do Comitê contra a demolição da prisão de La Petite Roquette, explicando as razões para a preservação do lugar, as quais estavam ligadas principalmente a sua "memória arquitetônica”. As manifestações públicas não tiveram sucesso, e da antiga prisão somente restou o portão de entrada que hoje dá acesso a uma bela praça. Soppelsa (2010a) aponta que o fracasso da batalha travada pela preservação da instituição foi consequência da indiferença do público em geral frente ao argumento unicamente científico trazido pelos intelectuais envolvidos, restrito unicamente ao valor excepcional da arquitetura do edifício, deixando de lado questões ligadas à memória.

Em 2014, o Jornal La Libération publicou duas matérias que evidenciam a preocupação de historiadores franceses com os rumos do patrimônio prisional na atualidade. As discussões convidam as autoridades públicas a refletirem sobre a memória desses lugares e seus vestígios, criando um espaço público para o debate. Entre os signatários do manifesto, intitulado "As prisões também fazem parte de nosso patrimônio", estão presentes nomes como Philippe Artières, Michelle Perrot e Jean-Claude Vimont ${ }^{20}$.

Artières aponta a ausência cada vez maior das prisões na paisagem urbana, devido às sistemáticas demolições. Uma das motivações que levou o passado prisional a ser objeto de comunicação - no mesmo ano em que as Jornadas do Patrimônio propuseram a visitação de La Santé - foi o péssimo estado de conservação da prisão de Fointainebleau ${ }^{21}$ em seu bicentenário. A prisão foi a leilão nesse mesmo ano e na ocasião não teve compradores. Instituída como patrimônio, cujo conjunto foi registrado em 1996 no Inventário Suplementar de Monumentos Históricos, o lugar abrigou o já mencionado Museu Nacional das Prisões, fechado em 2010.

Diferentemente do apelo da Associação para a Salvaguarda do Panóptico de La Petite Rocket (APSPPR) em 1974, os intelectuais que intercederam pelo espaço prisional em 2014 não estavam 
fundamentados apenas em argumentos arquitetônicos. A importância da "memória arquitetônica" é também mencionada, mas o que prevalece é a ênfase na preservação das memórias afetivas. Sob um apelo imbuído de consciência histórica, a demanda dos historiadores aponta que esses lugares de privação de liberdade não sejam também privados de memórias ${ }^{22}$. Conforme Artière:

Há na França outra herança, obscura esta [...], que dá para ver uma faceta menos gloriosa de nossa história que são prisões, asilos e outras instituições de restrição. [...] Conservar ou destruir paredes, preservar ou jogar fora arquivos é um gesto político.

O manifesto dos historiadores publicado em um jornal de grande circulação oferece legitimidade aos múltiplos discursos que cercam a discussão sobre as prisões e seus apagamentos na atualidade. A ideia não era fornecer uma resposta, uma solução para o problema, mas propor que uma pergunta fosse feita coletivamente: por que e para quem preservar o patrimônio prisional?, criando assim um espaço para o debate.

Contudo, de forma semelhante ao resultado obtido pelo grupo que em 1974 intercedeu contra a demolição da Petite Rockette, não parece ter ocorrido sensibilização do grande público, a sociedade se manteve indiferente. Apesar de um presente marcado por demandas sociais por história e por memória, e ainda que os argumentos dos historiadores não se centrassem apenas nos aspectos arquitetônicos, mas sim na ênfase nas memórias dos que passaram pelo lugar e seus rastros, a velha prisão de Fointainebleau foi vendida em 2016, com pouco alarde e discussão na imprensa. O projeto de revitalização ${ }^{23}$ do lugar prevê sua transformação em um prédio de apartamentos que, em tese, deve respeitar parte da estrutura original ${ }^{24}$.

Frente a esse cenário, é possível observar um movimento que procura apreender tais espaços através de variadas possibilidades de registros documentais em diferentes suportes, realizados por meio de pesquisa histórica e de campo, que intencionam captar o maior número possível de características do imóvel que será demolido. Um exemplo interessante é o de Grand La Roquette. No final do 
A patrimonialização e suas contradições: o patrimônio prisional...

século XIX, frente à iminente demolição do lugar e à impossibilidade de salvaguarda material, partiu-se para o registro daquilo que era possível armazenar, perpassando um mosaico de suportes que transitavam por estudos históricos, visitas virtuais, pesquisas e descrições detalhadas dos edifícios, campanhas fotográficas, exposições, remoção de relíquias e até reconstituições de celas em outros espaços prisionais (SOPPELSA, 2010a; 2010b).

Algo semelhante vem ocorrendo na atualidade em La Santé. O site Criminocorpus, que se propõe a oferecer um museu virtual da história da justiça, dos crimes e das penas, hospeda exposições temáticas e visitas virtuais a espaços prisionais. A proposta disponibiliza uma visita virtual à prisão de La Santé, com vídeos gravados durante as Jornadas do Patrimônio de $2014^{25}$. A visita é colocada como um "testemunho patrimonial”, além de permitir que funcionários "guardem a memória de seu local de trabalho". O site disponibiliza inúmeras fotografias, trabalhos acadêmicos, mapas e outros documentos relacionados a La Santé. Em 2019, com a finalização das obras, "os restos de uma arquitetura histórica de quase um século e meio desaparecerão para sempre”, conforme lamentam algumas notícias divulgadas pela imprensa sobre a ostensiva reforma pela qual a instituição está passando ${ }^{26}$. $\mathrm{O}$ patrimônio prisional francês será aos poucos reduzido a registros disponibilizados na internet?

\section{Patrimônio Prisional, Patrimônio Carcerário: um conceito em construção}

A movimentação mais explícita em torno do patrimônio prisional na França que vem ocorrendo ao longo dos últimos dez anos revela a complexidade e a urgência da discussão frente às sucessivas destruições das edificações prisionais. Concomitante a essas ameaças, é possível observar o surgimento de discussões que procuram tecer as especificidades de um conceito em construção: o de patrimônio prisional ou carcerário.

Em 2016, a Universidade de Rennes promoveu a Jornada de Estudos "Tomar os lugares de confinamento pelo patrimônio". A proposta ressaltava uma urgência: 
Em vista da extrema riqueza da prisão e da herança judicial francesas, é notável, no entanto, que pouco trabalho é dedicado ao processo de patrimonialização e aos usos desses lugares. De fato, enquanto o campo de pesquisa sobre a memória se mostra particularmente dinâmico, a memória do confinamento e sua patrimonialização continuam subtrabalhadas no espaço de pesquisa da língua francesa ${ }^{27}$.

O objetivo do evento, que reuniu pesquisadores de diferentes áreas, como a história, sociologia e criminologia, foi realizar um balanço do que vem sendo produzido e dos trabalhos realizados a respeito da preservação dos locais de reclusão e sistemas repressivos. $\mathrm{O}$ evento procurou enfatizar o patrimônio prisional como um campo ainda relativamente novo na França.

Da periferia ao centro: "há muito tempo negligenciado, este patrimônio está agora no centro de muitas questões" 28 , coloca a chamada de um dossiê da revista Histoire pénitentiaire de 2016, dedicado ao tema "Patrimônio e Arquitetura Prisional". O historiador Jean Claude Vimont, um dos signatários da convocatória publicada pelo La Libertation em 2014, falecido em 2015, professor da Université de Rouen e ex-orientando de Michelle Perrot, foi pioneiro ao tentar definir os contornos da noção de patrimônio prisional (ou patrimônio carcerário), propondo o surgimento de uma nova categoria patrimonial cercada por especificidades ${ }^{29}$.

Vimont criou um blog, pensado de forma cooperativa por estudantes do Mestrado em Patrimônio da Universidade de Rouen, propondo uma reflexão sobre este novo conceito:

O mundo das prisões francesas está passando por profundas mudanças nos primeiros anos do século XXI. Os antigos estabelecimentos são prometidos para a destruição. Esta seção oferece informações sobre seu passado, seu futuro, sua conversão ou sua destruição. Propõe uma reflexão sobre o novo conceito de 'patrimônio prisional'.

Em 2010, a realização do Colloque Larchitecture carcérale, des mots et des murs, organizado pela Ecole Nationale d'Administration 
Pénitentiaire, trouxe à tona a discussão sobre as especificidades desse tipo de patrimônio. Ao tecer o conceito de patrimônio prisional, Vimont $(2010,2014)$ salienta a importância de se transcender o limite das edificações para a definição do campo. Conforme o historiador, para além da arquitetura, a noção deve voltar-se aos "arquivos sensíveis", às marcas, inscrições e intervenções de qualquer ordem, deixadas pelos presos durante sua passagem pelo espaço prisional. Esses registros são considerados como parte das diferentes experiências de confinamento, de presos comuns, presos da repressão política, jovens em conflito com a lei etc.

Outra figura central nesse debate é a historiadora Caroline Soppelsa ${ }^{30}$. Com um trabalho voltado ao estudo da arquitetura prisional e inserida nos embates públicos que cercam a patrimonialização das prisões na França, seus estudos focam principalmente em casos parisienses, entre eles La Santé, questionando o papel "da memória (memória histórica, memória dos prisioneiros) na medida em que permite ou, ao contrário, impede o surgimento de consciência patrimonial das prisões" (2010). Sua participação no anteriormente citado documentário realizado pelo canal francês $R M C$ Découvert corrobora a reverberação dos debates propostos por historiadores na constituição do que está se configurando como um novo campo, ligado à patrimonizalição das prisões.

Soppelsa (2010) critica a ausência de políticas de preservação que pensem a respeito da memória dos presos comuns e, por consequência, a preservação de espaços prisionais que pensem o valor histórico em função de seus usos ordinários. Em 2008, Vimont alertava sobre a fragilidade dos grafites gravados por detentos nas paredes das prisões e suas potencialidades para o estudo desses lugares, instituindo-os como "fontes da escrita da história":

Entre as fontes da escrita da história, há umas mais frágeis do que outras, ameaçadas por sua própria materialidade, negligenciadas em favor de ricas coleções documentárias, relegadas à esfera dos apêndices iconográficos. $\mathrm{O}$ grafite prisional sofre de todas essas desvantagens, apesar dos esforços de alguns amadores, alguns antropólogos e alguns historiadores para incentivar sua conservação, inventariando-os e oferecendo possibilidades de análise (VIMONT, 2008, p. 195). 
Tais discussões possibilitam "entrelaçar a função original destes espaços aos sentidos históricos e patrimoniais a eles atribuídos" (BORGES, 2018a). Nesse caminho, a valoração patrimonial de lugares marginais pode contribuir para a desestigmatização dos sujeitos a eles ligados, "para que sobre eles se pense e se discuta, ajudando a diminuir os muros visíveis e invisíveis que separam os de dentro e os fora" das instituições de confinamento (BORGES, 2018a).

A tentativa de preservar essas marcas frágeis do passado prisional inscritas nas paredes das instituições reverbera em publicações e exposições fotográficas. A obra intitulada Prisons: Patrimoine de France é um exemplo nesse sentido (MADRANGES, 2013). O livro trouxe à tona 2400 fotografias realizadas em 460 estabelecimentos penitenciários franceses. Nessas imagens, é possível destacar as marcas deixadas pelos presos, como desenhos, grafites, pinturas e escritas em paredes e edificações.

Também em 2010 o Museu Carnavalet recebeu a exposição L'impossible photographie: Prisons parisiennes, com 3800 imagens que contavam a história das prisões parisienses, desde meados do século XIX até os dias atuais. Na ocasião, La Santé ganhou destaque como a única prisão ainda em funcionamento no perímetro urbano de Paris. Entre as imagens, os "registros sensíveis" ganhavam notoriedade juntamente com a monumentalidade dos edifícios.

Para Vimont (2014), "[...] o grafite preservado é apenas um dos atributos das instituições ameaçadas de destruição". Conforme apontado acima, no manifesto publicado no La Libertation em 2014, é ressaltada pelos historiadores a rapidez dos apagamentos dos espaços prisionais, e com isso a impossibilidade de serem estudados, frisando a importância desses espaços como "lugares de memória":

[...] nos últimos dez anos o estado vendeu suas velhas prisões degradadas no centro da cidade, substituindo-as por conjuntos gigantescos longe dos centros urbanos. Muitas prisões antigas são destruídas, muitas vezes sem dar tempo aos historiadores para estudar história, para acompanhar isso. Peças essenciais da história da arquitetura de nosso país, as prisões também são lugares de memória: os prisioneiros políticos, as vítimas judias de Vichy, mas também os 
A patrimonialização e suas contradições: o patrimônio prisional...

prisioneiros de direito comum, seus "sem voz”, que também são freqüentemente privados de memória e de toda uma sociedade ${ }^{31}$.

A velocidade da destruição tece uma história "em constante movimento, refletindo as comoções que se desenrolam diante de nós e sendo, portanto, objeto de uma renovação sem fim" (BÉDARIDA, 2000, p. 219-229). Essa história inacabada sofre com a perda física de parte importante de suas fontes. A valorização da arquitetura passa a ser acompanhada da tentativa de valorização da memória. $A$ atribuição de sentidos que confere à prisão o título emblemático de "lugar de memória" dessa vez parte dos historiadores. O conceito ajuda a conferir legitimidade ao caráter histórico desses espaços e às memórias dos "sem voz", privados de liberdade, e frente ao contexto de destruição dos lugares por eles habitados durante anos, privados também de memória. Aspectos esses ressaltados por Artière em 2014, no jornal La Libertation, em defesa da "herança obscura" representada pelo patrimônio prisional.

Os embates que cercam o patrimônio prisional na França foram comparados por Vimont (2014) à configuração do patrimônio industrial $^{32}$ na Europa entre os anos 1950 e 1960, período em que muitas edificações ligadas à arquitetura industrial foram demolidas. O patrimônio industrial teve seu reconhecimento reforçado em 2003 por meio da Carta de Nizhny Tagil sobre o patrimônio industrial, resultante da conferência promovida pelo The International Committee for the Conservation of the Industrial Heritage ${ }^{33}$. A Carta, voltada exclusivamente para a preservação do patrimônio industrial, contou com discussões de diferentes segmentos sociais, tanto amadores quanto profissionais, ligados à arqueologia industrial, história, arquitetura, engenharia, planejamento urbano etc. $\mathrm{O}$ documento volta-se a aspectos ligados às edificações e outros vestígios, como as ferramentas e maquinário, tanto quanto em registros mais sensíveis, voltados às memórias dos trabalhadores. Ao longo dos anos, a proliferação dos debates sobre o patrimônio industrial conquistou diferentes países, incentivando a realização de inventários ligados ao processo de industrialização (KÜHL, 2008; 2014). 
Inspirado na movimentação gerada por essas discussões, Vimont vislumbrava um movimento semelhante de discussão e valorização do patrimônio prisional por meio da realização de inventários em diferentes regiões francesas. A experiência estaria centrada nas edificações, mas também nos "traços frágeis" deixados pelos detentos:

O conceito de patrimônio prisional é recente e ainda é controverso, como no surgimento do patrimônio industrial. Seus contornos ainda não estão definidos com clareza. Os organismos de registro ou de proteção do patrimônio estão hesitantes, embora várias regiões do $\mathrm{DRAC}^{34}$ e serviços de Inventário estejam preocupados com a preservação destes traços frágeis (VIMONT, 2014).

Soppelsa (2010) questiona a existência de registros sistemáticos a respeito das prisões. Para a autora, "nenhum inventário sistemático ou grandes sínteses nacionais foram realizados até o momento na França”. Os estudos mais aprofundados são o resultado de iniciativas anglo-saxônicas. O sociólogo e criminologista americano Norman Johnston (2000) é citado pela autora como responsável por uma síntese internacional, financiada pela Comissão Real sobre os Monumentos Históricos da Inglaterra (English Heritage). Conforme Soppelsa (2010), Johnston seria o responsável pelo único inventário nacional sistemático sobre as prisões francesas feito até hoje, ainda pouco conhecido na França. Um dos resultados desse trabalho encontra-se disponível na internet, trata-se das listagens das plantas arquitetônicas doadas pelo pesquisador à Biblioteca Lloyd Sealy, em $2000^{35}$. O material é frágil e encontra-se disponível à pesquisa como parte das Coleções Especiais.

Em 2016, o Seminário Arquiteturas Restauradas teve como foco La Santé, propondo o tema "Arquitetura Prisional do século XIX à prova do século XXI", problematizando a "revitalização" da instituição. O evento procurou "reunir todos os interessados": pesquisadores, historiadores, arquitetos, administradores, patrocinadores, curadores, restauradores, empreiteiros etc. O evento chamou a atenção para as particularidades desse tipo de patrimônio:

Anos 90, Porto Alegre, v. 25, n. 48, p. 213-240, dez. 2018 
A patrimonialização e suas contradições: o patrimônio prisional...

Se 'as prisões também fazem parte de nossa herança', para usar o título de um apelo lançado por vários historiadores no Libération em 18 de setembro de 2014, o sítio da prisão de La Santé está particularmente revelando as dificuldades relacionadas aos sucessivos ajustes e revitalização de um lugar com grande carga simbólica, emblemático do aprisionamento do século XIX na França e com múltiplas restrições ${ }^{36}$.

No processo de reinvenção de La Santé, os termos revitalização e requalificação perpassam diferentes falas ${ }^{37}$. A revitalização preocupa-se em pensar novas funcionalidades estratégicas às áreas que possuem patrimônio, visando uma nova dinâmica urbana baseada na diversidade econômica e social” (MOURA et al., 2006). $\mathrm{Na}$ atualidade, o termo revitalização vem sendo substituído por requalificação urbana, propondo uma visão mais ampla e inclusiva:

[...] a requalificação apresenta propostas alicerçadas na recuperação e na valorização das origens e das verdadeiras representações sociais, humanizando e controlando o sistema de exclusão das cidades contemporâneas (se opondo ao sentido excludente do termo revitalização), e, ao mesmo tempo, reinventando identidades baseadas em produções socioculturais locais.

O discurso central da requalificação urbana evidencia a tentativa de inclusão social de uma população marginal em novos espaços sadios e revalorizados, onde relações sociais includentes seriam estabelecidas e reforçadas por novas funções urbanas (SOTRATTI, 2015).

Mais que restabelecer os danos estruturais ocasionados pela ação do tempo, ou propor a simples demolição de estruturas obsoletas, o projeto iniciado em 2014 em La Santé ressalta em sua proposta a busca por melhores condições aos presos, o respeito à fisionomia original em algumas partes do edifício, sua integração à cidade de forma harmônica, objetivando devolver à comunidade um espaço funcional e confortável. Busca-se, através do patrimônio 
reestruturado, garantir a sustentabilidade e promover benefícios para as gerações atuais e futuras. Tais objetivos se inscrevem na atual fase de refluxo do patrimônio indicada por Hartog (2017, p. 43-44), apontada anteriormente, trazendo questões complexas à preservação frente à necessidade de fazer uso do patrimônio para tornar mais habitável o presente. Se o patrimônio deve servir à vida, a busca por uma justa economia do patrimônio traz uma série de embates sobre como e o que preservar. Repensar sentidos patrimoniais dentro de um projeto que parece buscar soluções que confrontam a preservação e a manutenção de um local que se mantém com suas funções originais - e marginalizadas - há quase um século e meio, parecem ser desafios inexoráveis e difusos do fenômeno ainda recente ligado à patrimonialização dos espaços prisionais. Frente a esses desafios, os espaços prisionais do século XIX e XX sobreviverão ao século XXI?

O dossiê publicado pela Revista Histoire pénitentiaire em 2016, mencionado anteriormente, trouxe uma série de artigos que tratam da história de diversas prisões francesas demolidas, revitalizadas e/ou ameaçadas de destruição. Traz ainda exemplos localizados nos Estados Unidos e Suíça. A utilização da expressão "lugar de memória" como argumento para a preservação dos espaços prisionais é frequente em quase todos os textos. Relatos de experiências de implementação de museus e sensibilização das comunidades por meio de exposições e/ou visitas guiadas procuram mostrar alternativas, caminhos possíveis para a patrimonialização das prisões. Os textos são bem descritivos e procuram contextualizar esses espaços focando especialmente em sua arquitetura e em questões metodológicas ligadas às ações de preservação, apontando a necessidade do envolvimento da comunidade no reconhecimento desse tipo de patrimônio, pensando nos habitantes ao entorno e também nos sentenciados. Contudo, as discussões pouco aprofundam os debates teóricos ligados ao patrimônio cultural ou mesmo um refinamento do ainda incipiente conceito de patrimônio carcerário, mas contribuem significativamente para instaurar o tema como uma demanda do tempo presente ${ }^{38}$. 
A patrimonialização e suas contradições: o patrimônio prisional...

\section{Considerações finais}

Em 2016, a Jornada de estudos Un historien par-delà les hauts murs, organizada pela Universidade de Rouen, homenageou Vimont, falecido em 2015. Michelle Perrot escreve um texto que liga o historiador definitivamente ao universo carcerário: "Jean-Claude Vimont (1955-2015), historien de la prison”. Vimont era especialista em prisões, com publicações que abordam temas como a história dos presos políticos, da justiça juvenil, dos campos de concentração do século XX, a história das prisões etc. ${ }^{39}$ Pensando os rumos da história das prisões na atualidade, Vimont parece ter seu interesse pelo patrimônio prisional ligado à angústia de ver desaparecer espaços ainda não estudados pelos historiadores, em uma velocidade que atropela o vagar necessário à densidade das análises acadêmicas.

A noção de patrimônio prisional tem delineado as especificidades de um campo de pesquisa e atuação ainda em construção e perpassado por conflitos. A preocupação com a preservação das austeras edificações no tecido urbano se soma aos embates que cercam os vestígios ligados à memória e à dimensão mais sensível e pessoal da experiência de confinamento. $\mathrm{O}$ apelo à memória dos envolvidos no cotidiano prisional, os detentos, seus familiares e os funcionários das instituições, tem procurado o apoio público na tentativa de frear as destruições, sem ainda encontrar acolhida.

A preocupação de Vimont com os "traços frágeis", as "criações proibidas dos presos" (BORGES, 2016), contrasta com os sistemáticos apagamentos permitidos pelas demolições, reformas, revitalizações e/ou requalificações. Diante desse cenário, a solução que se delineia procura empreender uma salvaguarda que se agarra a variados suportes que permitam algum tipo de registro daquilo que está prestes a desaparecer, uma busca um tanto desesperada em tentar substituir a perda dos vestígios físicos. Visitas virtuais e inúmeras fotografias revelam a preocupante tendência que tem se desenhado como uma resposta frágil frente às destruições.

$\mathrm{Na}$ tessitura que cerca as discussões a respeito do patrimônio prisional, é possível observar ainda a ausência de uma reflexão a respeito da preservação dos acervos, documentais e/ou objetos tridimensionais, tais como documentos escritos, fotografias, uniformes, 
móveis e utensílios. Desses vestígios pouco se fala dentro da batalha que cerca o debate sobre esse tipo de patrimônio.

$\mathrm{O}$ conceito segue em construção enquanto as velhas prisões são varridas da trama urbana.

\section{CUSTODIAL PATRIMONY AND ITS CONTRADICTIONS: PRISONS AS PATRIMONIES IN FRANCE IN PRESENT TIME}

Abstract: This article focuses on struggles in practices of prisons as patrimonies in France. By approaching Prison de La Santé's case, open to public visit during the Patrimony Symposium in 2014, we intend to make clear the discussion and some theoretical and methodological implications as part of a concept construction - prison patrimony - which has been increasingly controversial in France in the last ten years. We analyze the questionable functions of some prisons of the XIX ${ }^{\text {th }}$ Century still in operation and/or disabled, monumental buildings made obsolete nowadays and marked by struggles in controversial actions for creating patrimonies, as well as we approach deeply some historians's roles in this process.

Keywords: Prison patrimony. Prisons. History of present time. France.

\section{Notas}

${ }^{1}$ Disponível em: $<$ https://francetvinfo.fr/france/journees-du-patrimoine/visitede-la-prison-de-la-sante-a-paris.html>. Acesso em: 20 mar. 2018.

${ }^{2}$ Disponível em: <https:/huffingtonpost.fr/2014/09/15/journees-patrimoine-prison-sante-ouvre-portes-visite-guidee_n_5823160.html>. Acesso em: 19 mar. 2018. Todas as traduções foram feitas pela autora.

${ }^{3} \mathrm{O}$ documentário do canal francês $R M C$ Découvert menciona essa tentativa de integrar o edifício à paisagem de Paris, permitindo que ele passe despercebido dentro da cidade.

${ }^{4}$ Terrorista venezuelano, conhecido como "o Chacal", que cumpria pena de prisão perpétua em La Santé desde 1997.

${ }^{5}$ Ex-ditador panamenho Manuel Noriega, condenado a sete anos de prisão pela lavagem de milhões de euros em contas bancárias e propriedades francesas na década de 1980. 
A patrimonialização e suas contradições: o patrimônio prisional...

${ }^{6}$ Célebre assaltante de bancos e conhecido por suas fugas espetaculares de penitenciárias de segurança máxima, entre elas a fuga realizada em La Santé em 1978.

${ }^{7}$ Oficial do Governo Francês de Vichy, colaborador do Regime Nazista durante a Segunda Guerra Mundial.

${ }^{8}$ Disponível em: <https://theguardian.com/world/2014/dec/07/la-sante-prison-paris-visitors-welcome>. Acesso em: 1 mar. 2018.

${ }^{9}$ Disponível em: <https://theguardian.com/world/2014/dec/07/la-sante-prison-paris-visitors-welcome>. Acesso em: 15 mar. 2018.

${ }^{10}$ Disponível em: $\langle$ https://criminocorpus.org/fr/visites/visite-virtuelle/la-sante/>. Acesso em: 28 ago. 2018.

${ }^{11} \mathrm{O}$ documento institui recomendações do Comitê de Ministros dos estados membros da União Europeia sobre as estratégias para o patrimônio cultural europeu para o século XXI, e é datado de 22 de fevereiro de 2017. Conforme o documento: "A estratégia para o património cultural europeu para o século XXI tem as suas raízes em diversas realizações do Conselho da Europa que contribuíram, após a adoção da Convenção Cultural Europeia, para desenhar as políticas patrimoniais da maior parte dos países europeus e a cooperação que se estabeleceu entre eles. Assenta também nos trabalhos levados a cabo pela UNESCO e pela União europeia, e no quadro das reflexões de organizações não-governamentais internacionais e de redes centradas no património, que foram associadas à presente estratégia”. Disponível em: <http://anoeuropeu. patrimoniocultural.gov.pt/index.php/estrategia-para-o-patrimonio-cultural-europeu-para-o-seculo-xxi/>. Acesso em: 31 ago. 2018.

${ }^{12}$ Disponível em: <http://anoeuropeu.patrimoniocultural.gov.pt/wp-content/ uploads/2017/08/Estratégia-para-o-Património-Cultural-para-o-século-XXI-. pdf>. Acesso em: 5 mar. 2018.

${ }^{13}$ Disponível em: <https://youtube.com/watch?v=fzFRNM3RkC4>. Acesso em: 3 set. 2018.

${ }^{14}$ Disponível em: <https://theguardian.com/world/2014/dec/07/la-sante-prison-paris-visitors-welcome >. Acesso em: 20 abr. 2018.

${ }^{15}$ Disponível em: <https://lexpansion.lexpress.fr/actualites/1/actualite-economique/medecin-chef-a-la-sante-l-absurdite-de-la-prison-declinee-dans-unfilm_1174324.html >. Acesso em: 20 abr. 2018.

${ }^{16} \mathrm{O}$ Museu abrigava um acervo referente à história da administração prisional.

${ }^{17}$ A Petit La Roquette funcionou como prisão para menores e depois de 1935 como prisão para mulheres. A Grand La Roquette, destinada aos presos homens, 


\section{Viviane Trindade Borges}

era conhecida pelas execuções por meio da guilhotina, a última delas ocorrida em 1899, dias antes de seu fechamento e transferência dos condenados para La Santé. As prisões de La Roquette foram criadas em Paris em 1830 e fechadas definitivamente em 1974.

${ }^{18}$ Prisão La Petite Roquette, AMC, n. 33, mar. 1974, p. 86-87. Médiathèque du Patrimoine, arquivos, 0081 / 075-11 / 0024.

${ }^{19}$ Disponível em: $\langle$ https://criminocorpus.hypotheses.org/16>. Acesso em: 10 mar. 2018.

${ }^{20}$ Disponível em: <http://liberation.fr/societe/2014/09/18/les-prisons-font-aussi-partie-de-notre-patrimoine_1103194>. Acesso em: 12 mar. 2018.

${ }^{21}$ Disponível em: <http://liberation.fr/societe/2014/09/18/a-vendre-ancienne-maison-d-arret_1103515>. Acesso em: 20 abr. 2018.

${ }^{22}$ Disponível em: <http://liberation.fr/societe/2014/09/18/a-vendre-ancienne-maison-d-arret_110351>. Acesso em: 23 mar. 2018.

${ }^{23}$ A proposta de revitalização (na França réhabilitacion) procura promover estratégias pensadas para áreas dotadas de patrimônio, visando a dinamizar a diversidade econômica e social nesses espaços. "Essa estratégia, adotada de forma precursora pela cidade de Barcelona, na Espanha, disseminou-se por diversas cidades do mundo assumindo diferentes denominações idiomáticas: gentrification, no Reino Unido; rehabilitation/refurbishment e renovation, nos EUA; réhabilitacion, na França; rehabilitación, na Espanha, são algumas denominações empregadas em programas que adotam tal estratégia” (SOTRATTI, 2015). ${ }^{24}$ Disponível em: <http://leparisien.fr/fontainebleau-77300/fontainebleau-1-ancienne-prison-sera-transformee-en-appartements-14-06-2016-5883785.php〉. Acesso em: 10 mar. 2018.

${ }^{25}$ Disponível em: <https://criminocorpus.org/fr/visites/en-prison/visite-prison-paris-la-sante/>. Acesso em: 10 mar. 2018.

${ }^{26}$ Disponível em: $<$ https://francetvinfo.fr/france/journees-du-patrimoine/visitede-la-prison-de-la-sante-a-paris.html>. Acesso em: 30 mar. 2018.

${ }^{27}$ Disponível em: 〈https://calenda.org/400854?file=1〉. Acesso em: 10 mar. 2018.

${ }^{28}$ Patrimoine et architecture carcérale. Chamadas de trabalhos. Revista Calenda, 7 abr. 2015. Disponível em: 〈https://calenda.org/323589>. Acesso em: 30 mar. 2018.

${ }^{29}$ Disponível em: <https://criminocorpus.org/fr/expositions/art-et-justice/lamemoire-des-murs/>. Acesso em: 20 mar. 2018.

${ }^{30}$ Caroline Soppelsa é historiadora, doutora em História da Arte e Arquitetura Contemporânea. Disponível em: 〈http://data.bnfffr/16915391/caroline_soppelsa/>

Anos 90, Porto Alegre, v. 25, n. 48, p. 213-240, dez. 2018 
A patrimonialização e suas contradições: o patrimônio prisional...

e <https://cairn.info/revue-societes-et-representations-2010-2-p-83.htm>. Acesso em: 28 jul. 2018.

${ }^{31}$ Disponível em: <http://liberation.fr/societe/2014/09/18/les-prisons-font-aussi-partie-de-notre-patrimoine_1103194>. Acesso em: 20 mar. 2018.

${ }^{32}$ A respeito do Patrimônio Industrial, ver KÜHL, 2008; 2014; MENEGUELLO, 2009; 2006.

${ }^{33}$ Órgão criado em 1978 e principal responsável internacional pelas discussões que cercam a preservação do patrimônio industrial.

${ }^{34}$ Direction Régionale des Affaires Culturelles.

${ }^{35}$ Disponível em: 〈http://guides.lib.jjay.cuny.edu/SpecialCollections〉. Acesso em: 3 set. 2018.

${ }^{36}$ Disponível em: <https://criminocorpus.hypotheses.org/21000>. Acesso em: 5 set. 2018.

${ }^{37}$ A respeito de um maior aprofundamento desses conceitos, ver: VARGAS; CASTILHO, 2006.

${ }^{38}$ A esse respeito, ver: MATHURIN; STALDER, 2016; PRUVOT, 2016; BERTRAND, 2016; BERTREUX, 2016; HERBELOT, 2016; ABDELA, 2016; PETITQUENCEZ, 2016; BOURDEAU; PIERRE, 2016; SANCHEZ, 2016; ELK, 2016; RUEDIN; ELSIG, 2016; VUILLEUMIER, 2016; FINK, 2016; GARÇON, 2016. ${ }^{39}$ Cito algumas destas publicações: VIMONT, 1989; 1993; 2004; 2005; 2010. A respeito da obra de Vimont, ver: 〈http://grhis.univ-rouen.fr/grhis/?page_id=683〉. Acesso em: 11 fev. 2018.

\section{Referências}

ABDELA, Sophie. Par-delà les murs: l'urbanité carcérale dans le Paris du XVIIIe siècle. Revue Histoire Pénitentiare, v. 11, 2016. Disponível em: <https://criminocorpus.hypotheses.org/19309>. Acesso em: 23 maio 2018.

BÉDARIDA, François. Tempo presente e presença da história. In: FERREIRA, Marieta; AMADO, Janaína (Org.). Usos \& abusos da história oral. 3. ed. Rio de Janeiro: FGV Editora, 2000. p. 219-229.

BERTRAND, Étienne. L’ancienne prison de Bourg-en-Bresse (Ain). Revue Histoire Pénitentiare, v. 11, 2016. Disponível em: <https://criminocorpus.hypotheses. org/19315>. Acesso em: 23 maio 2018. 


\section{Viviane Trindade Borges}

BERTREUX, Julien. Fontevraud, une histoire pénitentiaire aujourd'hui assumée. Revue Histoire Pénitentiare, v. 11, 2016. Disponível em: <https://criminocorpus. hypotheses.org/19358>. Acesso em: 23 maio 2018.

BORGES, Viviane Trindade. Como a História Pública pode contribuir para a preservação dos patrimônios difíceis? In: MAUAD, Ana; SANTHIAGO, Ricardo; BORGES, Viviane. Que história pública queremos? São Paulo: Letra e Voz, 2018a.

. Memória pública e patrimônio prisional: questões do tempo presente. Tempo e Argumento, Florianópolis, v. 10, n. 23, p. 310-332, jan./mar. $2018 \mathrm{~b}$.

. Carandiru: os usos da memória de um massacre. Tempo e Argumento, Florianópolis, v. 8, n. 19, p. 4-33. set./dez. 2016.

BOURDEAU, Marie; PIERRE, Michel. Saint-Laurent-du-Maroni, De la préservation d'une mémoire à sa mise en valeur. Revue Histoire Pénitentiare, v. 11, 2016. Disponível em: 〈http://criminocorpus.hypotheses.org/18879>. Acesso em: 23 maio 2018.

CARTA DE NIZHNY TAGIL sobre o patrimônio industrial. 17 jul. 2003.

CHAUVAUD, Frédéric. Jean-Claude Vimont: la prison. À l'ombre des hauts murs. Revue d'histoire de l'enfance irrégulière, n. 7, 6 fev. 2005. Disponível em: <http://journals.openedition.org/rhei/403〉. Acesso em: 23 maio 2018.

COMBESSIE, Philippe. La ville et la prison, une troublante cohabitation. Revue Projet, Ilha de França, n. 269, p. 70-76, 2002.

DELACROIX, Christian. A história do tempo presente, uma história (realmente) como as outras? Tempo e Argumento, Florianópolis, v. 10, n. 23, p. 39-79, jan./ mar. 2018.

ELK, Sara Jane. Eastern State Penitentiary Historic Site, Philadelphia Pennsylvania. Revue Histoire Pénitentiare, v. 11, 2016. Disponível em: <https://criminocorpus.hypotheses.org/26013>. Acesso em: 23 maio 2018.

. Le site historique du pénitencier de Eastern State, Philadelphie, Pennsylvanie, États-Unis. Revue Histoire Pénitentiare, v. 11, 2016. Disponível em: <https://criminocorpus.hypotheses.org/26007>. Acesso em: 23 maio 2018.

FIZE, Michel. Une prison dans la ville. Histoire de la prison modèle de la Santé (1867-2014). Préface de Robert Badinter. Paris: Buchet/Chastel, 2015. 222 p.

FINK, Daniel. Le patrimoine carcéral de la Suisse: son émergence et ses formes. Revue Histoire Pénitentiare, v. 11. Patrimoine et architectute carcérale, 2016. Disponível em: 〈https://criminocorpus.hypotheses.org/19749>. Acesso em: 23 maio 2018. 
A patrimonialização e suas contradições: o patrimônio prisional...

FOUCAULT, Michel. Vigiar e Punir. História da violência nas prisões. Rio de Janeiro: Vozes, 2002.

GARÇON, Jack. L'espace Pierre Cannat dédié à la mémoire pénitentiaire à l'École nationale d'administration pénitentiaire (ENAP, Agen, France). Revue Histoire Pénitentiare, v. 11. Disponível em: <https://criminocorpus.hypotheses. org/19399>. Acesso em: 23 maio 2018.

HARTOG, François. Crer em história. Belo Horizonte: Autêntica, 2017.

HERBELOT, Lydie. Les métamorphoses de Clairvaux. Revue Histoire Pénitentiare, v. 11, 2016. Disponível em: 〈https://criminocorpus.hypotheses.org/19079〉. Acesso em: 23 maio 2018.

JOHNSTON, Norman Bruce. Norman Bruce Johnston Collection of Prison Architectural Plans. Special Collections of the Lloyd Sealy Library John Jay College of Criminal Justice. Collection arranged and described by Ellen Sexton, Fall 2000.

KÜHL, Beatriz. Preservação do patrimônio arquitetônico da industrialização: problemas teóricos de restauro. Cotia, SP: Ateliê Editorial, 2008.

. Algumas questões relativas ao patrimônio industrial e à sua preservação. Disponível em: <http://portal.iphan.gov.br/uploads/publicacao/algumas_ questoes_relativas_ao_patrimonio.pdf $>$. Acesso em: 23 nov. 2017.

MANDRES, Ethienne. Prisons: Patrimoine de France. Paris: LexisNexis, 2013.

MAGNANI, José Guilherme Cantor. Pensar grande o patrimônio cultural. Lua Nova, v. 3, n. 2, p. 62-67, 1986. Disponível em: <http://dx.doi.org/10.1590/ S0102-64451986000300011>. Acesso em: 23 maio 2018.

MENEGUELLO, Cristina. Vazios Urbanos. In: FORTUNA, Carlos; LEITE, Rogério Proença. Plural de Cidade: novos léxicos urbanos. 1. ed. Coimbra: Almedina, 2009. p. 127-138.

. Industrial heritage in Brazil: approaches and perspectives. In: INTERNATIONAL CONGRESS OF THE INTERNATIONAL COMMITTEE FOR THE CONSERVATION OF THE INDUSTRIAL HERITAGE, 13., Itália, 2006. Proceedings... Itália: [s.n.], 2006.

MATHURIN, Clémentine; STALDER, Florian. La maison centrale de Fontevraud, un patrimoine! Revue Histoire Pénitentiare, v. 11, 2016. Disponível em: <https://criminocorpus.hypotheses.org/19604>. Acesso em: 23 maio 2018. MARTIN, Laurent. Les politiques du patrimoine en France depuis 1959. Politiques de la culture: carnet de recherches du Comité d'histoire du ministère de la 


\section{Viviane Trindade Borges}

Culture sur les politiques, les institutions et les pratiques culturelles, [s.1.], 2015. Disponível em: <https://chmcc.hypotheses.org/1367>. Acesso em: 3 ago. 2018. MOURA, Dulce; GUERRA, Isabel; SEIXAS, João; FREITAS; Maria João. A revitalização urbana: contributos para a definição de um conceito operativo. Cidades, Comunidades e Territórios, Lisboa, n. 12/13, p. 15-34, dez. 2006.

NORA, Pierre. Entre memória e história: a problemática dos lugares. Projeto História, São Paulo, n. 10, dez. 1993, p. 7-28.

PERROT, Michelle. As crianças da Petite-Roquette. Revista Brasileira de História, São Paulo, v. 9, n. 7, 1989.

PETIT-QUENCEZ, Blandine. L'histoire du patrimoine lié au bagne en NouvelleCalédonie, du non-dit à l'affirmation identitaire. Revue Histoire Pénitentiare, v. 11, 2016. Disponível em: 〈https://criminocorpus.hypotheses.org/18816〉. Acesso em: 23 maio 2018.

POULOT, Dominique. Uma história do patrimônio no Ocidente. São Paulo: Estação liberdade, 2009.

PRUVOT, Stéphanie. Musée du château de Mayenne. La valorisation d'un site à l'histoire entremêlée. Revue Histoire Pénitentiare, v. 11, 2016. Disponível em: <https://criminocorpus.hypotheses.org/19656>. Acesso em: 23 maio 2018.

ROUSSO, Henry. A última catástrofe. A história, o presente, o contemporâneo. Rio de Janeiro: FGV, 2016.

RUEDIN, Pascal; ELSIG, Patrick. Le Pénitencier, centre d'expositions des Musées cantonaux du Valais à Sion (Suisse): du bâtiment par défaut au bâtiment assumé. Revue Histoire Pénitentiare, v. 11, 2016. Disponível em: <https://criminocorpus. hypotheses.org/19900>. Acesso em: 23 maio 2018.

SANCHEZ, Jean-Lucien. Sur les traces du comte de Monte-Cristo et de la dernière reine de France: révolution française, littérature et tourisme. Revue Histoire Pénitentiare, v. 11, 2016. Disponível em: <https://criminocorpus.hypotheses. org/28578>. Acesso em: 23 maio 2018.

SANTOS, Myriam Sepúlveda dos. Ruínas e testemunhos: o lembrar através de marcas do passado. Revista de Ciências Sociais, Fortaleza, n. 39, p. 221-239, out. 2013.

SOPPELSA, Caroline. Architecture pénitentiaire. Mémoire historique: l'ambivalence des représentations. Sociétés \& Représentations, n. 30, p. 83-96, 2010.

. Photographie et sauvegarde du patrimoine. Les prisons de Paris, objets d'architecture et d'histoire. In: BEAUJARD, Gilles. L'Impossible Photographie: Prisons parisiennes (1851-2010). Paris: Paris-Musée, 2010. p. 156-163.

Anos 90, Porto Alegre, v. 25, n. 48, p. 213-240, dez. 2018 
A patrimonialização e suas contradições: o patrimônio prisional...

SOTRATTI, Marcelo Antônio. Revitalização (verbete). In: REZENDE, Maria Beatriz et al. (Org.). Dicionário IPHAN de Patrimônio Cultural. Rio de Janeiro; Brasília, DF: IPHAN; DAF; Copedoc, 2015.

SUBRAHMANYA, Sanjay. Connected histories. Notes towardo a reconfiguration of earlt modern Eursia. In: LIEBERMAN, V. (Ed). Beyond binary histories: re-imagining Eurasia c. 1830. Ann Arbor: The University of Michigan Press, 1977. p. 289-315.

VARGAS, Heliana; CASTILHO, Ana Luisa (Org.). Intervenções em centros urbanos. Objetivos, estratégias e resultados. São Paulo: Editora Malone, 2006.

VASSEUR, Veronique. Medecin-chef a la prison de la Santé. Canadá: Kobo Editions, 2012.

VIMONT, Jean-Claude (Org.). Jeunes, déviances et identités du XVIIIe au XXe siècle. Cahiers du Ghris, Rouen, n. 15, 2005. 157 p.

. Punir autrement. Les prisons de Seine-Inférieure pendant la Révolution. Rouen: CRDP, 1989. 144 p.

. La prison politique en France. Genèse d'un mode d'incarcération spécifique (XVIIIe-XXe siècles). Paris: Anthropos-Economica, 1993. 503 p.

. Graffiti en péril? Sociétés \& Représentations, n. 25, p. 193-202, 2008.

. Sous l'œil de l'expert. Les dossiers judiciaires de personnalité, Rouen, n. 22, 2010.

. La prison. À l'Ombre des hauts murs. Paris: Gallimard, 2014. 128 p.

. La mémoire des murs. 2014. Disponível em: 〈https://criminocorpus. org/fr/expositions/art-et-justice/la-memoire-des-murs/>. Acesso em: 23 jul. 2017.

VUILLEUMIER, Christophe. Histoire comparative des prisons de ChampDollon et du Bois-Mermet. Revue Histoire Pénitentiare, v. 11, 2016. Disponível em: <https://criminocorpus.hypotheses.org/19794>. Acesso em: 23 maio 2018. WALBY Kevin; PICHÉ Justin. The polysemy of punishment memorialization: dark tourism and Ontario's penal history museums. Punishment and Society, v. 4, n. 13, p. 451-472, 2011.

WELCH, Michael. Escape to Prison: Penal Tourism and the Pull of Punishment. Berkeley, University of California Press, 2015.

Recebido em: 27/04/2018

Aprovado em: 01/09/2018

Anos 90, Porto Alegre, v. 25, n. 48, p. 213-240, dez. 2018 